\title{
Short communication: Preference for flavored concentrate premixes by dairy cows
}

\author{
M. T. Harper, ${ }^{*}$ J. Oh, ${ }^{*}$ F. Giallongo, ${ }^{*}$ J. C. Lopes, ${ }^{*}$ H. L. Weeks, ${ }^{*}$ J. Faugeron, $†$ and A. N. Hristov*1 \\ ${ }^{*}$ Department of Animal Science, The Pennsylvania State University, University Park 16802 \\ †Pancosma, $\mathrm{CH}-1218$ Geneva, Switzerland
}

\begin{abstract}
Flavor preferences may be used to stimulate feed intake in dairy cows, which may improve use of robotic milking systems and increase feed intake of sick cows. A cafeteria-design experiment was used to determine if dairy cows have flavor preferences. Sixteen lactating Holstein cows averaging $197 \pm 32 \mathrm{~d}$ in milk, $1.9 \pm$ 0.8 lactations, $27.8 \pm 4.2 \mathrm{~kg} / \mathrm{d}$ of dry matter intake, and $41.5 \pm 7.4 \mathrm{~kg} / \mathrm{d}$ of milk yield were involved in the experiment. Cows were offered 7 flavored concentrate premixes (FCP) and 1 control premix. The FCP flavors were anise, fenugreek, honey, orange, thyme, molasses, and vanilla; the absence of flavor, neutral, acted as a control. The inclusion rate of the flavors in FCP was 250 to $300 \mathrm{~g} / \mathrm{t}$ on an as-is basis. Cows were not adapted to the flavors before the experiment. Cows were housed in a tiestall barn and offered, on each day, 4 different FCP (1 kg each) in plastic bins placed in front of each cow. The experiment lasted 6 consecutive days. Each FCP was presented to each cow once every $2 \mathrm{~d}, 2 \mathrm{~h}$ after the morning feeding. Flavors and position of the bins in front of the cows were randomized. As a result, each flavor was presented to each cow 3 times during the experiment, at 3 different bin locations. Each cow had access to the FCP for 5 min from the time they started eating. Eating time and amount eaten were recorded. The vanilla and fenugreek FCP were consumed the most, at 408 and $371 \mathrm{~g} / 5$-min offering, respectively, whereas the orange and anise FCP were consumed the least, at 264 and $239 \mathrm{~g} / 5$-min offering, respectively. Similarly, cows spent the most time eating the vanilla and fenugreek FCP at 99 and 75 s/offering, respectively, and the least amount of time eating the orange and anise FCP at 49 and 50 s/offering, respectively. We detected an effect of bin position: the 2 center FCP were consumed more than the outer 2 FCP. Flavor had no effect on consumption rate. In conclusion, relative
\end{abstract}

Received February 8, 2016.

Accepted April 18, 2016.

${ }^{1}$ Corresponding author: anh13@psu.edu to the control, concentrate intake was not affected by flavor, but dairy cows may prefer vanilla or fenugreek flavors when offered a novel choice.

Key words: feed intake, flavor preference, dairy cow

\section{Short Communication}

Cows use their senses to discriminate between feeds (Goatcher and Church, 1970). Cattle choose between multiple feeds in a range of environments, from forage selection on a pasture to sorting behavior when fed a TMR (Hardison et al., 1954; Maulfair and Heinrichs, 2013). Ruminants use sight, smell, taste, and touch to choose their feed (Goatcher and Church, 1970). Cows have the ability to recognize the 5 basic tastes of sweet, bitter, salty, sour, and umami, and some work has been done to investigate effect of taste on feed preference in ruminants (Goatcher and Church, 1970; Ginane et al., 2011). Flavors are often added to calf starters to stimulate and improve the consumption of dry feed (Morrill and Dayton, 1978; Thomsen and Rindsig, 1980). Certain categories of dairy cows, such as cows in early lactation or sick cows that are off feed, could benefit from highly preferred feed, which may stimulate overall TMR DMI. Similarly, identifying flavor preferences of dairy cows may help in managing commercial herds using robotic milking systems or facilitate the use of specialized scientific sampling equipment such as the GreenFeed system (C-Lock Inc., Rapid City, SD) in research herds. Feeds with sweet flavors have been shown to increase consumption in early lactation cows at least over a few days (Nombekela et al., 1994). Spörndly and Åsberg (2006) conducted a series of short-term experiments with Swedish Red and White dairy heifers to find a concentrate that would most entice cows to come voluntarily to a robotic milking unit. They found a preference for pelletized mixtures of primarily barley, oats, and sugarbeet pulp over 20 other nonpelletized feeds including ground barley, soybean meal, and rapeseed meal. A limitation to using the taste of a feed to entice an animal to eat is that the animal must first prehend the feed. Scent may be a more useful stimulus for feed 
intake because the volatile compounds responsible for smell are dispersed over a large area. In a robotic milking system, scent could be detected by the cow without the cow having to first enter the robot. Feed preference in animals can be difficult to elucidate. Preference in ruminants is greatly affected by the postingestive feedback caused by a feed's nutrient and toxin contents (Provenza et al., 1996; Favreau et al., 2010). Kyriazakis and Oldham (1993), for example, reported that lambs selected diets based on protein needs. Dohi et al. (1991) reported that odor from cattle feces deterred cows from consuming feed. Sodium deficiency in cattle caused an increased olfactory sensitivity to salt (Bell and Sly, 1983).

The hypothesis of the current experiment was that dairy cattle would show preferences for flavors in concentrate mixes. Flavor preferences were tested only by adding different synthetic commercial flavorings to a neutral base premix to keep the feed's appearance, taste, texture, and nutrient content the same.

All animals involved in the experiment were cared for according to the guidelines of the Pennsylvania State University Institutional Animal Care and Use Committee. The committee reviewed and approved the experiment and all procedures carried out in the study. A cafeteria experiment utilizing 16 healthy lactating Holstein cows averaging $197 \pm 32$ DIM, $1.9 \pm 0.8$ lactations, $27.8 \pm 4.2 \mathrm{~kg} / \mathrm{d}$ of DMI, and $41.5 \pm 7.4 \mathrm{~kg} / \mathrm{d}$ of milk yield was conducted to test cow preferences for 8 different flavored concentrate premixes (FCP). The FCP, in nonpelletized meal form, was $47 \%$ ground corn, $30 \%$ canola meal, $20 \%$ cottonseed hulls, and $3 \%$ soybean oil on a DM basis. The inclusion rate of the synthetically derived flavors in the FCP was $300 \mathrm{~g} / \mathrm{t}$ (as-is basis) for anise (6426, Pan-Anise 426; flavor code and flavor name, respectively), fenugreek (6402, Pan-Fen 402), and orange (A60-3134, Pan Juicy Orange), and $250 \mathrm{~g} / \mathrm{t}$ for vanilla (6051, Vanille-Pan 870.051), honey (A61-3324, Pan Tek Wild Blossom Honey), thyme (6400, PanThym 400), and molasses (A61-3011, Pan Molasses), as recommended by the manufacturer (Pancosma S.A., Geneva, Switzerland) to yield equivalent intensities of smell. Cows were not adapted to the synthetic flavors before the experiment, although molasses was included in the TMR. Cows were housed in a tiestall barn at the Penn State Dairy Research and Teaching Center and were fed, once daily at approximately $0830 \mathrm{~h}$, a TMR diet consisting of (DM basis) corn silage, $40 \%$; alfalfa haylage, 20\%; candy byproduct meal (Graybill Processing, Elizabethtown, PA), 8.9\%; ground corn grain, $7.7 \%$; canola meal, $6.8 \%$; molasses, $5.0 \%$; cracked corn grain, $4.4 \%$; whole roasted soybeans, $3.7 \%$; and mineral premix, $3.5 \%$. Cows were fed this diet for $14 \mathrm{~d}$ before initiation of the experiment. Two hours after feeding on
6 consecutive experimental days, the TMR in front of the cows was removed and a wooden frame holding 4 plastic bins $(24 \mathrm{~cm} \times 37 \mathrm{~cm}$; Figure 1$)$ containing different FCP was offered to each cow. The order of FCP in front of the cows was randomized by bin position (1, $2,3,4$, with bins 1 and 4 being in the outside positions) and day of offering ( 1 or 2 ). Cows were offered 4 FCP on offering day 1 and the other 4 on offering day 2 for 6 consecutive days (Table 1), resulting in the cows being offered each FCP 3 times during the experiment. Every FCP was offered once every $2 \mathrm{~d}$. Bin positioning was randomized across the trial such that every position had each flavor at least 11 times but not more than 13 times. Bins were positioned 1 to 4 from the right of the cow to the left. Each plastic bin contained $1 \mathrm{~kg}$ of FCP. The FCP was offered for a period of 5 min starting after the cow crossed the imaginary plane of the opening of any FCP bin with her muzzle. Continuous time sampling was used to record which bin the cow was eating from at any given time. Eating was defined to have begun when a cow's tongue touched the FCP or its muzzle touched the FCP and it began to move its jaw. Eating was defined to have stopped for an FCP when chewing of the FCP ceased while the cow's head was raised out of a bin or eating began on another FCP. At the end of the 5-min offering period, the wooden frame with the different FCP was removed, the TMR replaced, and the bins weighed to determine individual FCP intake based on the difference between starting and ending FCP weight. The total time spent eating for each 5-min interval was later summed for each FCP for statistical analysis. The absence of flavor acted as a neutral control (i.e., concentrate mix only). The FCP were mixed using a Hobart mixer, in approximately $25-\mathrm{kg}$ batches, a few days before the experiment, stored at $2^{\circ} \mathrm{C}$ in sealed ziplock bags without headspace, and opened only on the experimental days to prevent flavor loss or cross contamination.

Data were analyzed using the MIXED procedure of SAS (2002-2012; SAS Institute Inc., Cary, NC). The model contained FCP, bin, and the FCP $\times$ bin interaction. Cow was a random effect and all others were fixed. Results were declared significant at $P \leq 0.05$ and a trend toward significance at $0.05<P \leq 0.10$. When the main effects of treatment or bin were significant, means were separated by a pairwise $t$-test (pdiff option of PROC MIXED). Data are presented as LS means.

The amounts consumed, time spent eating, and consumption rate are shown in Table 2. Vanilla was consumed more $(P \leq 0.008)$ than anise and orange. We detected no difference between amounts consumed of the neutral control and any of the flavored FCP. Cows spent more $(P \leq 0.005 ; P=0.06$ vs. fenugreek) time eating vanilla $\mathrm{FCP}$ than anise, honey, molasses, orange, 


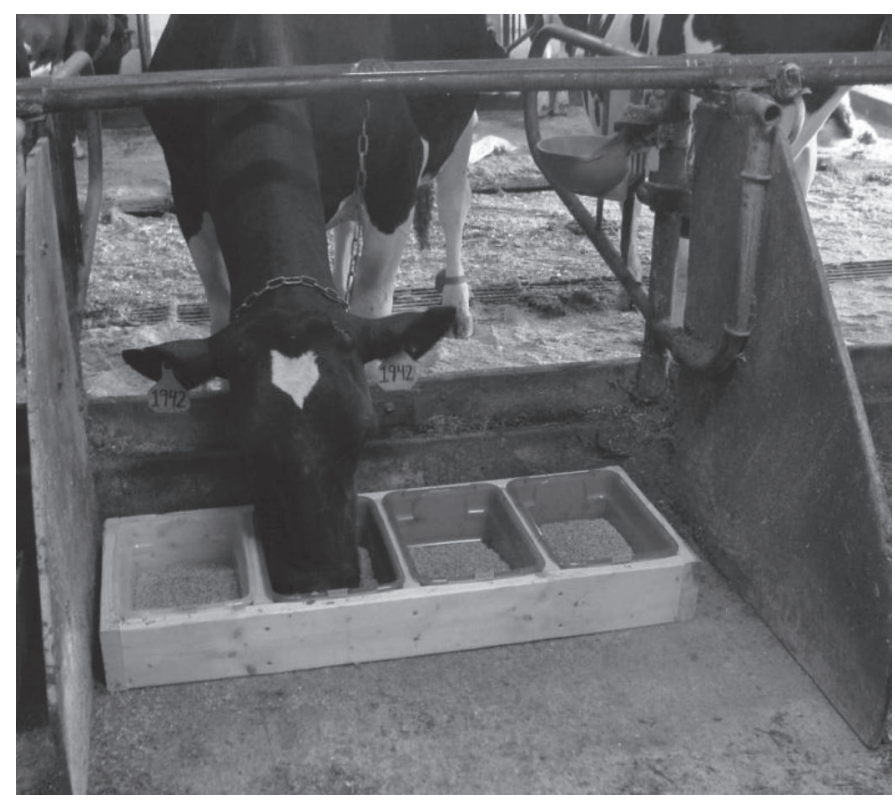

Figure 1. A cow eating flavored concentrate premix (FCP).

or thyme FCP. Additionally, the neutral and fenugreek FCP were consumed longer $(P \leq 0.05)$ than was the orange FCP. No differences in consumption rates were detected among any of the FCP. Bin positioning affected $(P<0.001)$ the amount consumed, time spent eating, and consumption rate. Bins 2 and 3 (i.e., the 2 inside bins) had the greatest $(P \leq 0.005)$ amounts consumed, and cows spent the most time $(P \leq 0.003)$ eating from them. Bin 1 had the lowest $(P<0.001)$ amounts consumed and the least $(P<0.001)$ amount of time spent eating from it, whereas bin 4 was intermediate. Consumption rate was greater $(P \leq 0.04)$ for bin 3 compared with bins 1 and $4(P=0.47$ compared with bin 2$)$ and was least for bin $1(P \leq 0.04)$. There was no flavor $\times$ bin interaction for time spent eating and consumption rate, but we detected a trend $(P=0.07)$ for the amount consumed. Examination of the data, however, showed a similar low consumption from bin 1 across FCP. Satiety might have played a role in the reduced consumption from bin 1 as the other bins were more often eaten from first; bin 2 was eaten from first
38 times, bin 3 also 38 times, bin 4 was first 11 times, and bin 1 was first only 6 times.

Although this study did not show a difference between the control (neutral) and any of the flavored FCP for the amount consumed, differences were observed among flavors. It should be emphasized that the neutral FCP had no added flavors, but flavors were intrinsic to the ground corn, canola meal, cottonseed hulls and soybean oil used in every FCP, including the neutral one. Cattle preferences are affected by prior eating experiences via postingestive feedback, which may help explain why we found no differences between the neutral premix and the flavored FCP because the nutrient feedback would have been the same for all treatments (Provenza, 1995). Feeds can generate what is known as sensory-specific satiety, which in the context of this experiment means that satiety may have been reached for one flavor, causing the cow to consume another, albeit possibly less preferred, flavor (Rolls, 1986). In an experiment conducted by Provenza et al. (1996), sheep did not solely eat their most preferred flavor but selected various flavors when given a choice. Although it may be unlikely that sensory-specific satiety occurred for most of the flavors in the short 5-min offerings of this experiment, this type of satiety may have played a role in the lesser intake of the molasses FCP because molasses was included in the TMR. Anise was one of the least consumed flavors, with cows eating it for less time than vanilla. Similarly, Nombekela et al. (1994), in a preference ranking test with early lactation dairy cows, ranked anise the lowest below a control, control plus monosodium glutamate, control plus molasses, and control plus alfalfa treatment. In a flavor preference study by Thomas et al. (2007), unflavored drinking water was preferred over an orange-flavored drinking water available at the same time. Similarly, orange flavor in a concentrate premix was not preferred by lactating cows in the current study.

It is interesting that consumption rate was not influenced by flavor but was strongly influenced by bin position. This is probably because cows were more often eating first from the inner bins and the eating rate may have decreased within the 5-min sampling time due to satiety. Bin position also affected the amount consumed

Table 1. Order of flavor offerings to dairy cows in the experiment

\begin{tabular}{|c|c|c|c|c|c|c|}
\hline \multirow[b]{2}{*}{ Item } & \multicolumn{6}{|c|}{ Day of experiment } \\
\hline & 1 & 2 & 3 & 4 & 5 & 6 \\
\hline $\begin{array}{l}\text { Day of } \mathrm{FCP}^{1} \text { offering } \\
\text { FCP offered }\end{array}$ & $\begin{array}{l}1 \\
1,2,3,4^{2}\end{array}$ & $\begin{array}{l}2 \\
5,6,7,8\end{array}$ & $\begin{array}{l}1 \\
3,8,5,2,\end{array}$ & $\begin{array}{l}2 \\
6,1,4,7\end{array}$ & $\begin{array}{l}1 \\
2,5,4,1\end{array}$ & $\begin{array}{l}2 \\
8,3,6,7\end{array}$ \\
\hline
\end{tabular}




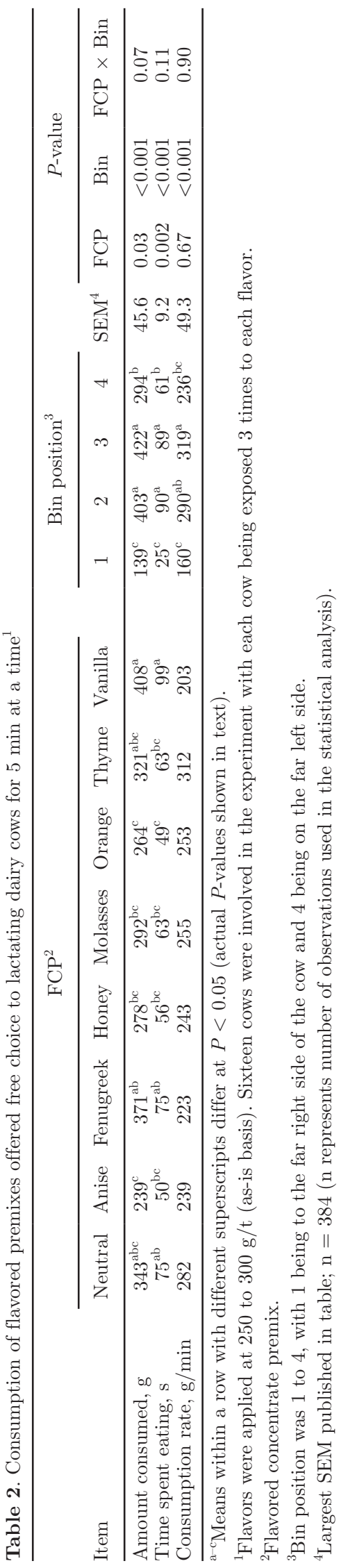

and time spent eating, with the middle bins directly in front of the cow yielding higher values. Eating from the outside bins might have been mildly uncomfortable to the cows because of their close proximity to the solid plywood partitions between stalls in the feed bunk causing their ears to, at times, touch the partition. A possible spatial effect must always be taken into account when designing a cafeteria study. In the current experiment, flavor positioning was randomized so that every flavor was in each bin position between 11 and 13 times across the study. Day of offering for each flavor was not the same, neighboring flavors in the wooden frame were not uniform, and flavor position randomization was unique to each cow.

Flavor preferences can be short term, as demonstrated by Nombekela et al. (1994), who reported a preference and increased DMI for a diet including 1.5\% sucrose for $5 \mathrm{~d}$, and in a later study by Nombekela and Murphy (1995), who reported no increase in DMI during a 12-wk study with similar feedstuffs. Feed preferences in ruminants are highly affected by the nutrient content of the feed (Provenza et al., 1996). Cattle flavor sensitivity is affected by the feed they consume. For example, feeding corn silage increases a cow's sensitivity to sweet tastes and decreases sensitivity to sour tastes (Albright, 1993). Similarly, lamb preferences were affected by diet in a study by Wang and Provenza (1996), where lambs fed a high-energy diet preferred a high-protein supplement and lambs fed a high-protein diet preferred a high-energy supplement. Preferences and aversions to feeds and flavors can be conditioned by ruminal infusions of various substances including sodium propionate, sodium acetate, lithium chloride, and starch (Launchbaugh and Provenza, 1994; Villalba and Provenza, 1997, 2000).

Feed preference in ruminants is affected by many variables that likely interact with one another. Based on the current study, it appears that smell is one of the variables affecting feed preference and that vanilla and fenugreek may be some of the preferred scents. This might have practical use in production scenarios such as robotic milking systems. Further research should be done in this area to elucidate whether individual cattle have unique preferences, whether preferences change through reproductive stages, whether cows adapt to scents, and whether entrained preferences can be effectively used in a commercial setting.

\section{REFERENCES}

Albright, J. L. 1993. Feeding behavior of dairy cattle. J. Dairy Sci. 76:485-498.

Bell, F. R., and J. Sly. 1983. The olfactory detection of sodium and lithium salts by sodium deficient cattle. Physiol. Behav. 31:307312. 
Dohi, H., A. Yamada, and S. Entsu. 1991. Cattle feeding deterrents emitted from cattle feces. J. Chem. Ecol. 17:1197-1203.

Favreau, A., R. Baumont, G. Ferreira, B. Dumont, and C. Ginane. 2010. Do sheep use umami and bitter tastes as cues of post-ingestive consequences when selecting their diet? Appl. Anim. Behav. Sci. 125:115-123.

Ginane, C., R. Baumont, and A. Favreau-Peigné. 2011. Perception and hedonic value of basic tastes in domestic ruminants. Physiol. Behav. 104:666-674.

Goatcher, W. D., and D. C. Church. 1970. Taste responses in ruminants. 1. Reactions of sheep to sugars, saccharin, ethanol and salts. J. Anim. Sci. 30:777-783.

Hardison, W. A., J. T. Reid, C. M. Martin, and P. G. Woolfolk. 1954. Degree of herbage selection by grazing cattle. J. Dairy Sci. 37:89102.

Kyriazakis, I., and J. D. Oldham. 1993. Diet selection in sheep: The ability of growing lambs to select a diet that meets their crude protein requirements. Br. J. Nutr. 69:617-629.

Launchbaugh, K. L., and F. D. Provenza. 1994. The effect of flavor concentration and toxin dose on the formation and generalization of flavor aversions in lambs. J. Anim. Sci. 72:10-13.

Maulfair, D. D., and A. J. Heinrichs. 2013. Eating behavior, ruminal fermentation, and milk production in lactating dairy cows fed rations that varied in dry alfalfa hay and alfalfa silage content. Livest. Sci. 151:179-187.

Morrill, J. L., and A. D. Dayton. 1978. Effect of feed flavor in milk and calf starter on feed consumption and growth. J. Dairy Sci. 61:229-232.

Nombekela, S. W., and M. R. Murphy. 1995. Sucrose supplementation and feed intake of dairy cows in early lactation. J. Dairy Sci. $78: 880-885$.
Nombekela, S. W., M. R. Murphy, H. W. Gonyou, and J. I. Marden. 1994. Dietary preferences in early lactation cows affected by primary tastes and some common feed flavors. J. Dairy Sci. 77:23932399.

Provenza, F. D. 1995. Postingestive feedback as an elementary determinant of food preference and intake in ruminants. J. Range Manage. 48:2-17.

Provenza, F. D., C. B. Scott, T. S. Phy, and J. J. Lynch. 1996. Preference of sheep for foods varying in flavors and nutrients. J. Anim. Sci. 74:2355-2361.

Rolls, B. J. 1986. Sensory-specific satiety. Nutr. Rev. 44:93-101.

Spörndly, E., and T. Åsberg. 2006. Eating rate and preference of different concentrate components for cattle. J. Dairy Sci. 89:2188-2199.

Thomas, L. C., T. C. Wright, A. Formusiak, J. P. Cant, and V. R. Osborne. 2007. Use of flavored drinking water in calves and lactating dairy cattle. J. Dairy Sci. 90:3831-3837.

Thomsen, N. K., and R. B. Rindsig. 1980. Influence of similarly flavored milk replacers and starter on calf starter consumption and growth. J. Dairy Sci. 63:1864-1868.

Villalba, J. J. and F. D. Provenza. 1997. Preference for flavored wheat straw by lambs conditioned with intraruminal infusions of acetate and propionate. J. Anim. Sci. 75:2905-2914.

Villalba, J. J., and F. D. Provenza. 2000. Postingestive feedback from starch influences the ingestive behaviour of sheep consuming wheat straw. Appl. Anim. Behav. Sci. 66:49-63.

Wang, J., and F. D. Provenza. 1996. Food preference and acceptance of novel foods by lambs depend on the composition of the basal diet. J. Anim. Sci. 74:2349-2354. 